\title{
A systematic review of task- shifting for HIV treatment and care in Africa
}

\author{
Mike Callaghan*1, Nathan Ford ${ }^{2,3}$ and Helen Schneider ${ }^{3}$
}

\begin{abstract}
Background: Shortages of human resources for health $(\mathrm{HRH})$ have severely hampered the rollout of antiretroviral therapy (ART) in sub-Saharan Africa. Current rollout models are hospital- and physician-intensive. Task shifting, or delegating tasks performed by physicians to staff with lower-level qualifications, is considered a means of expanding rollout in resource-poor or HRH-limited settings.

Methods: We conducted a systematic literature review. Medline, the Cochrane library, the Social Science Citation Index, and the South African National Health Research Database were searched with the following terms: task shift*, balance of care, non-physician clinicians, substitute health care worker, community care givers, primary healthcare teams, cadres, and nurs* HIV. We mined bibliographies and corresponded with authors for further results. Grey literature was searched online, and conference proceedings searched for abstracts.

Results: We found 2960 articles, of which 84 were included in the core review. 51 reported outcomes, including research from 10 countries in sub-Saharan Africa. The most common intervention studied was the delegation of tasks (especially initiating and monitoring HAART) from doctors to nurses and other non-physician clinicians. Five studies showed increased access to HAART through expanded clinical capacity; two concluded task shifting is cost effective; 9 showed staff equal or better quality of care; studies on non-physician clinician agreement with physician decisions was mixed, with the majority showing good agreement.

Conclusions: Task shifting is an effective strategy for addressing shortages of HRH in HIV treatment and care. Task shifting offers high-quality, cost-effective care to more patients than a physician-centered model. The main challenges to implementation include adequate and sustainable training, support and pay for staff in new roles, the integration of new members into healthcare teams, and the compliance of regulatory bodies. Task shifting should be considered for careful implementation where HRH shortages threaten rollout programmes.
\end{abstract}

\section{Introduction}

Sub-Saharan Africa suffers from the world's most pronounced crisis in human resources for health: 36 of the 57 countries that now face health worker shortages are in Africa [1]. These shortages intensify--and are intensified by--the HIV/AIDS pandemic. Much interest has recently been paid to how to streamline HIV care, both to offer high-quality care to patients and expand access to care. One response to this shortage has been the reassignment of clinical roles by shifting tasks to different cadres of health workers: nurses may become involved in prescribing drugs, lay counsellors involved in testing, new cadres may be introduced to perform specific tasks, and patients

* Correspondence: mike.callaghan@utoronto.ca

1 Department of Anthropology, University of Toronto, Canada Full list of author information is available at the end of the article may be engaged to take over some elements of their own care. The objective is a streamlined, rationalized chain of care that relieves pressure on each worker involved while maintaining quality standards for patients and increasing access to interventions.

Task shifting is not new. In 19th century France, Officiers de Santé [2] were an officially recognized and commonly used class of non-physician health care worker, while in China, so-called barefoot doctors were widely deployed across the country in the mid-20th century [3]. In Africa, non-physician clinicians have long been trained across the continent to fill various roles [4-6]. Systematic reviews from various areas of health care provision support the general conclusion that good health outcomes can be achieved by task shifting to nurses [7] and lay or community health workers [8-10]. 
The potential for task shifting in HIV care was elaborated by the World Health Organization's 2004 publication of Integrated Management of Adult and Adolescent Illness guidelines, which recommended that nurses and clinical aids be trained to provide primary care for HIV [11]. In 2008, this potential was expanded and formalized by joint WHO/UNAIDS/PEPFAR guidelines for the implementation of task shifting [12] as an immediate way to address staff shortages while delivering good quality care. However, the rapidly emerging evidence from subSaharan Africa, where task shifting is seen as most relevant, has not been systematically reviewed. Such analysis is important, since task shifting has been the subject of some debate. Critics have argued that task shifting has become a "bandwagon" that is uncritically championed at the expense of existing health cadres, whose low pay and poor working conditions drive high attrition [13]. Several commentators have noted that even though this approach may be able to provide increased quality care for HIVpositive patients, task shifting should not be a substitute for investments in health care systems more generally [14-17], and that even the best staffing models will be inadequate in areas with an absolute shortage of all levels of staff [18]. Concern has also been expressed that shifting additional HIV tasks to lower cadres could risk competing with other service priorities $[19,20]$, particularly given the overall shortage of nurses [21]. In some areas, community health workers already stand in when nurses when are unavailable [22,23].

These concerns underscore the need for careful, critical analysis, particularly where task shifting policies rewrite the job descriptions of some cadres. If task shifting is already widespread in practice, if not in policy, the process should be formalized and rationalized for the long term. This includes ensuring staff competencies and adequate working conditions [24]. This perspective takes for granted the unavoidable necessity of task shifting, and focuses on the need for a timely and logical policy response.

\section{Methods}

We developed a search strategy combining the following search terms: "task shift*" AND "balance of care OR nonphysician clinician OR substitute health worker OR community care giver OR primary health care team OR cadres OR nurs*" AND "HIV". Using these terms, we searched the following databases from inception to May 2009: Medline via PubMed, Social Science Citation Index, the South African National Health Research Database, and all the Cochrane Library. The abstract databases of all International AIDS Society Conferences (up to Cape Town, July 2009), all Conferences on Retroviruses and Opportunistic Infections (up to Montreal, Feb- ruary 2009), and all HIV/AIDS Implementers Meetings (up to Windhoek, 2009) were searched. This search was complemented by reviewing the bibliographies of relevant papers and grey literature review, and by personal communication with researchers in the field.

Our review included all articles that detailed approaches to task shifting for the delivery of HIV care in Africa. Abstracts were initially screened by one reviewer (MC) and agreement for final inclusion was sought with other authors (HS, NF).

Although the search methodology was systematic, the paucity and heterogeneity of the results prevent the drawing of systematic conclusions on any particular task shifting practice. We therefore subsequently organized the findings within the context of current debates about task shifting as policy and practice according to five main themes: efficiency; access; quality of care; health outcomes; and team dynamics.

\section{Results}

Our initial search yielded 2960 articles of which 84 were included in the core review. These included articles reporting outcomes (51), review articles (15), opinion pieces and position papers (12), papers elaborating theories and models (13), and policy analysis studies (6). Of those that reported outcomes, 25 were original articles (Table 1); the rest were supplementary presentations of the same study or programme.

\section{Efficiency}

We found evidence that task shifting increases programme efficiency. Several studies have quantified time saved by implementing task shifting on the assumption that delegating tasks gives senior clinical staff more time to deal with complicated patients. Time savings are an important outcome for HIV care and could help in addressing bottlenecks in treatment. Authors of a large study in Rwanda assessed time savings from nurse-initiated and monitored antiretroviral therapy (ART), and concluded that such task shifting at the national level would result in a $183 \%$ increase in doctor capacity for non-HIV related tasks [25,26]. Reductions in waiting times and loss-to-follow-up have also been observed in task shifted HIV care models [27-30].

Doctor salaries can be the largest cost of running an antiretroviral clinic. One South African study found that doctor salaries constituted roughly $42 \%$ of all clinic costs, including utilities and supplies [31]. Reducing dependence on doctors for ART could reduce clinic operating costs, or increase patient load for the same cost. A study comparing total average annual clinic-level cost per ART patient in Uganda and South Africa found that mean costs were almost a third less in the former (\$US331 vs 
Table 1: Characteristics and outcomes of studies on the impact of task-shfting in HIV/AIDS care

\begin{tabular}{|c|c|c|c|c|c|}
\hline Study & Setting & Study design & Study size & Intervention & Outcomes \\
\hline $\begin{array}{l}\text { Apondi et al, } 2007 \text { [65]; Tugume et } \\
\text { al } 2009 \text { [66]. }\end{array}$ & Uganda (rural) & Cohort & 2522 & $\begin{array}{l}\text { 'Field officers' provide home- } \\
\text { based ART }\end{array}$ & $\begin{array}{l}\text { Cumulative outcomes at } 4 \text { years showed excellent adherence }(96.8 \% \\
\text { were }>95 \% \text { adherent) and }<1 \% \text { defaulting. Social improvements: } \\
\text { reduced stigma, stronger family and community relationships }\end{array}$ \\
\hline Arem et al, 2009 [69]. & Uganda (rural) & Qualitative Survey & --- & Peer adherence supporters & $\begin{array}{l}\text { Peer health workers successfully understood ART regimens and physical } \\
\text { danger signs; } 97 \% \text { of clinic staff reported that peer health workers } \\
\text { improved patient outcomes. }\end{array}$ \\
\hline Bedelu et al, 2007 [40]. & South Africa (rural) & Cohort & 1025 & Decentralized, nurse-initiated ART & $\begin{array}{l}\text { Task-shifted, decentralised care increases access and is more acceptable } \\
\text { to patients loss-to-follow-up was clinics } 2 \% \text { at clinics compared to } 19 \% \text { at } \\
\text { hospital for comparable virological and immunological outcomes. }\end{array}$ \\
\hline Bolton-Moore et al, 2007 [50] & Zambia (urban) & Cohort (paediatric) & 2938 & $\begin{array}{l}\text { Nurse- and clinical officer-initiated } \\
\text { paediatric ART }\end{array}$ & $\begin{array}{l}\text { Decentralization allows for dramatically scaled-up rollout; cumulative 3- } \\
\text { year mortality }(8.3 \%) \text { and defaulting (5.4\%) comparable to other } \\
\text { programmes. }\end{array}$ \\
\hline Chang et al, 2008 [74] & Uganda (rural) & Cohort & 360 & $\begin{array}{l}\text { Patients trained as 'peer health } \\
\text { workers' to monitor ART } \\
\text { adherence by mobile phone }\end{array}$ & $\begin{array}{l}\text { Extremely cost effective. } 72 \% \text { retention and } 86 \% \text { virological suppression } \\
\text { at } 2 \text { years }\end{array}$ \\
\hline Chiambe et al, 2009 [42]. & $\begin{array}{l}\text { Kenya } \\
\text { (urban and rural) }\end{array}$ & Cohort & 39,900 & $\begin{array}{l}\text { Lay health care workers } \\
\text { supporting basic clinic tasks and } \\
\text { adherence counselling }\end{array}$ & Enrollment increased from 1,176 to 39,900 patients within 3 years \\
\hline Chung et al, 2008 [25] & Rwanda (rural) & Modelling & 3194 & Nurse-initiated ART & $\begin{array}{l}\text { Substantial time savings: nurse-initiated ART reduces physician HIV- } \\
\text { related workload by } 78 \% \text {, saving up to } 56 \text { hours physician time/month. }\end{array}$ \\
\hline Cohen et al, 2009 [55]. & Lesotho (rural) & Cohort & 4,347 & Nurse-initiated ART & $\begin{array}{l}\text { Favourable outcomes at } 12 \text { months among adults }(9.3 \% \text { mortality, } 2.5 \% \\
\text { defaulting) and children ( } 5 \% \text { mortality, } 2 \% \text { defaulting) }\end{array}$ \\
\hline Gimbel-Sherr et al 2008 [48]. & Mozambique & Cohort & 6,006 & $\begin{array}{l}\text { ART initiated by mid-level workers } \\
\text { ( } 2.5 \text { years training) vs doctors }\end{array}$ & $\begin{array}{l}\text { Patients seen by NPCs ( } 69.4 \% \text { of cohort) were } 44 \% \text { less likely to be lost to } \\
\text { follow up; no difference in mortality }\end{array}$ \\
\hline Jaffar et al, 2009 [59]. & Uganda (rural) & RCT & 859 & Home vs clinic-based ART delivery & $\begin{array}{l}\text { Similar outcomes of mortality and viral suppression in home-based and } \\
\text { faculty-based ART }\end{array}$ \\
\hline Koenig et al 2004 [35]. & Haiti (rural) & Cohort & 2300 & $\begin{array}{l}\text { Decentralized, CHW-monitored } \\
\text { ART }\end{array}$ & $\begin{array}{l}\text { Approach increases access, reduces defaulting, and delays resistance to } \\
\text { first-line medication }\end{array}$ \\
\hline
\end{tabular}


Table 1: Characteristics and outcomes of studies on the impact of task-shfting in HIV/AIDS care (Continued)

\begin{tabular}{|c|c|c|c|c|c|}
\hline McGuire et al, 2008 [29]. & Malawi (rural) & Cohort & 1676 & $\begin{array}{l}\text { Nurses/medical assistants } \\
\text { initiating and managing ART }\end{array}$ & $\begin{array}{l}\text { More rapid time to initiation ( } 21.5 \text { days for nurses/medical assistants vs } 35 \\
\text { days for clinical officers); no difference in outcomes and retention rates }\end{array}$ \\
\hline Sanjana et al, 2009 [73]. & Zambia & Cross-sectional survey & --- & $\begin{array}{l}\text { Assessment of record-keeping } \\
\text { errors among lay vs health care } \\
\text { workers }\end{array}$ & $\begin{array}{l}\text { Error rate for lay counsellors was less }(6.44 / 1,000 \text { field) than health care } \\
\text { workers }(16.81 / 1,000 \text { fields) }\end{array}$ \\
\hline Shulman et al, 2009 [50]. & Malawi (rural) & Cohort & --- & $\begin{array}{l}\text { Lay workers trained as pharmacist } \\
\text { assistants }\end{array}$ & $\begin{array}{l}\text { Expanded pharmacy capacity (500 prescriptions per day) and reduced } \\
\text { errors (30\% to } 5 \%)\end{array}$ \\
\hline Shumbusho et al, 2008 [47]. & Rwanda (rural) & Concordance study & --- & Nurses trained in ART initiation & Discordance between eligibility and initiation $<1 \%(n=343)$ \\
\hline Shumbusho 2008 [47]. & Rwanda (rural) & Cohort & 3194 & Nurse-initiated ART & Mortality at defaulting $<5 \%$ at 12 months. \\
\hline Tweya et al, 2008 [64]. & Malawi (rural) & Cohort & 1,617 & $\begin{array}{l}\text { Lay-workers to pre-screen for adult } \\
\text { ART eligibility }\end{array}$ & $\begin{array}{l}\text { Symptom screening checklist had high sensitivity (91.8\%) but low } \\
\text { specificity }(28 \%)\end{array}$ \\
\hline Tootla et al 2007 [53]. & South Africa (urban) & Cohort & 2,084 & Nurse/pharmacist managed ART & $75 \%$ of clients had undetectable viral load at 12 months \\
\hline Torpey et al 2008 [27]. & Zambia & $\begin{array}{l}\text { Cohort (quantitative } \\
\text { and qualitative } \\
\text { analysis) }\end{array}$ & 500 & $\begin{array}{l}\text { Lay-workers used as 'adherence } \\
\text { supporters' }\end{array}$ & $\begin{array}{l}\text { Lay adherence supporters reduced loss-to-follow-up from 15\% to 0\%; } \\
\text { reduced wait times }\end{array}$ \\
\hline Udegboka et al, 2009 [28]. & Nigeria & Cohort & --- & $\begin{array}{l}\text { Nurse ART treatment and peer } \\
\text { support }\end{array}$ & Task shifting reduced waiting times by 4 hours \\
\hline Van Rie et al 2009 [46]. & DRC (urban) & $\begin{array}{l}\text { Blinded concordance } \\
\text { study }\end{array}$ & 339 & $\begin{array}{l}\text { Nurse vs doctor decisions to } \\
\text { initiate ART }\end{array}$ & $95 \%$ agreement \\
\hline Van Griensven et al, 2008 [57]. & Rwanda (urban) & Cohort & 315 & $\begin{array}{l}\text { Nurse-initiated and monitored } \\
\text { paediatric ART }\end{array}$ & $84 \%$ retention and $83 \%$ virological suppression at 2 years \\
\hline $\begin{array}{l}\text { Van Griensven et al, } 2009 \\
\text { [58]. }\end{array}$ & Rwanda (urban) & Cohort & 435 & $\begin{array}{l}\text { Nurse-initiated and monitored } \\
\text { Adult ART }\end{array}$ & $0.3 \%$ attrition and $8.5 \%$ mortality at 1 year \\
\hline Wood et al, 2009 [45]. & South Africa (urban) & RCT & 812 & Doctor vs nurse-initiated ART & $\begin{array}{l}\text { Non-inferiority according to virological failure, toxicity, adherence, and } \\
\text { mortality. }\end{array}$ \\
\hline Zachariah et al, 2007 [62]. & Malawi (rural) & Cohort & 1634 & Community support vs no support & $26 \%$ increase in survival; $98 \%$ reduction in loss to follow up. \\
\hline
\end{tabular}


\$US892) and concluded that task-shifting may have helped to reduce clinic costs and improve overall efficiency [32].

\section{Access}

Efficiencies make possible increased access and affordability. Several studies have also reported an increase in access to counselling and testing through task shifting and the up-training of clinic staff [33-37]. In Botswana, the training of nurses to prescribe and dispense medication increased uptake of antiretroviral therapy, with nearly 20,000 patients receiving treatment at rural clinics as of December 2007 [38]. In Zambia, intensive training in a task shifted model of ART rollout was able to expand treatment access substantially without compromising quality of care [39]. In Lusikisiki, South Africa, districtwide access to ART was achieved within 2 years with a task-shifted model of care [40]. Similar scale up has been reported in Mozambique [41], Kenya [42], and Swaziland [43]. Finally, a costing study from Malawi found that district-wide access to ART using a non-physician model of care was achieved for an additional \$2.5 per capita, well within the estimated minimal basic health package costs (WHO) [44].

\section{Quality of care}

Provider performance is a crucial indicator, since lowerlevel cadres who require constant supervision, or who under-refer or over-refer patients, will save neither time nor money, nor improve the health of their patients. Several studies have evaluated task shifting against a gold standard of care.

We know of only one randomized controlled trial that has assessed the effectiveness of task-shifting for HAART delivery in sub-Saharan Africa. That study found that nurse-managed ART was non-inferior to doctor-managed ART in urban clinics in Johannesburg and Cape Town, South Africa: both treatment arms had similar outcomes of viral suppression, adherence, toxicity and death [45]. A study done in the Democratic Republic of Congo looked at concordance between doctor and nurse decisions to initiate ART and found $95 \%$ agreement on ART initiation [46]. Similarly in Rwanda, nurses accurately determined ART eligibility for more than $99 \%$ of patients [47]. In Mozambique, patients seen by mid-level workers (with 2.5 years training) were almost $30 \%$ more likely to have $\mathrm{CD} 4$ counts done at 6 months post ART initiation than those seen by doctors, and were $44 \%$ less likely to be lost to follow-up. There were no significant differences in mortality, CD4 counts done at 12 months, or adherence rates [48]. Finally, a study from Malawi found that the training of lay workers as pharmacy assistants reduced prescribing errors by $25 \%$ by unburdening the system [49].

\section{Health outcomes}

Several studies have assessed patient health outcomes in HIV services where tasks have been shifted to nurses and lay workers, against internationally accepted standards. A study of nurse-initiated and managed paediatric ART in Zambia--the largest-ever developing-world study of its kind--showed good clinical outcomes [50]. Similarly, a study of a primarily nurse-driven ART program in Kampala, Uganda, reported very good clinical outcomes after 2 years [51]. In each of these examples, the high level of performance of task shifted workers has occurred in a context of in-depth training and ongoing support. The need for ongoing training was highlighted by a study in Mozambique where expert clinicians oversaw the work of mid-level providers and found errors in antiretroviral management in over $40 \%$ of cases; errors were associated with duration since pre-service training [52].

A decentralized programme in rural South Africa involved mainstreaming uncomplicated HIV care to lower-level cadres (specifically, nurses and adherence counsellors) in clinics [40]. In a cohort study of 1025 patients, loss-to-follow-up at the decentralized clinics was $2.2 \%$, compared with $19.3 \%$ at the relatively centralised hospital, and patients with CD4 > 200 was $87.1 \%$ compared with $14.2 \%$. Other programmes in South Africa have reported similarly good outcomes for patients managed by non-physician health workers [53]. Nurse-managed programmes in Lesotho [54,55] and Rwanda [56-58] have also reported highly satisfactory outcomes in terms of mortality and retention-in-care for both adults and children.

Home-based care, treatment support, and other extraclinical services provided by lay health workers have been shown to be effective in sub-Saharan Africa. A randomized trial in Uganda [59] comparing home-based and facility-based care also found similar rates of viral load suppression, failure and mortality. A community-based program offering home-based ART through lay providers in Uganda achieved excellent outcomes without recourse to regular clinic visits [60]. Adherence to antiretroviral therapy improved after the introduction of lay counsellors and field officers $[60,61]$, with a study from Malawi showing that patients who were offered community support had significantly better survival and retention-incare rates compared with patients who did not receive such support [61]. In one Malawian study [62], however, community health workers did a worse job of identifying eligible patients for ART than did clinicians. These findings point to the limits to which tasks can be shifted, and underline the need to address the question of what tasks can be delegated, and to whom.

Non-medical patient outcomes have also been measured in task shifted models of care. In Uganda, the 
implementation of home-based ART through community health workers is associated with positive social outcomes, including an increase in social and family support and strengthened relationships [63-66].

\section{Team dynamics}

The process of task shifting can influence the social dynamics within clinics. An ethnographic study of a task shifted ART scale-up program in Cameroon [67] found a pervasive tension between nurses and community health workers, and ambiguity around the definitions of roles and hierarchies within the clinic. It concluded that task shifting policies must anticipate this problem and clearly delineate processes and responsibilities for existing and newly-created health cadres.

One recent South African study [68] suggested that task shifting leads not only to higher job satisfaction among staff, but to lower workload and usage of sick leave. The same study, however, reported higher staff turnover and poorer physical state of premises at taskshifted clinics. A qualitative survey done in rural Uganda found that almost all clinic staff interviewed $(97 \% ; n=37)$ strongly agreed or agreed that peer health workers improved the care of patients, and $86 \%$ strongly agreed or agreed that peer health workers had made their own jobs easier [69]. In a structured survey conducted among 62 national or provincial managers and HIV clinic staff in Mozambique, respondents indicated that non-physician clinicians should initiate ART for adults (100\%), pregnant women (95\%), and patients with tuberculosis (83\%) [70]. In an evaluation of a programme in Uganda and Zambia where lay counsellors provided basic triage, intensive adherence support and assistance in the provision of ART, their performance was rated as good or very good by $97 \%$ of health providers who were interviewed $(\mathrm{n}=$ 42); acceptability was also 97\% [71].

The importance of ongoing training has been highlighted by qualitative interviews. Community health workers in South Africa [72] report a desire for better training and supervision to meet the formidable challenges posed by the synergy of HIV, tuberculosis and poverty. Similarly, a study done in Zambia found that additional training needs were identified by almost $85 \%$ of lay counsellors [73].

Finally, task shifting is recognized as a valuable way to increase patient involvement in care [74]. People living with HIV/AIDS represent a largely untapped pool of treatment supporters, which will continue to grow apace with prevalence. These people are also more likely to remain in their communities than more mobile highercadre health workers [75]. Their involvement as active participants in health care delivery will require the negotiation of new power dynamics between patients and care givers and training and supervision where appropriate.

\section{Assessment of methodological quality of studies}

We undertook an assessment of methodological quality for the original studies included in this review (Additional File 1). The criteria related to quality included: sampling, methodology (comparative design or not, including randomization), use of objective outcomes, and discussion on sources of bias and generalizeability of findings. Of the 25 original studies included in this review, 11 included a comparative approach; for 2 studies randomization was done. Most studies (21) used objective outcome measures. Twelve studies were published as fully peer reviewed articles (the rest appeared as conference abstracts), allowing for a more complete assessment. Among these, all employed an appropriate statistical analysis, but only half (6) discussed potential sources of bias. The majority (11) included discussion about the generalizability of findings.

\section{Discussion and Conclusion}

The challenges facing Africa's health care system in responding to the human resource crisis urgently require policies and practices based on robust, policy-relevant evidence [76]. Although formal cost effectiveness studies have not been done, the available evidence for task shifting in HIV care supports the conclusion that it is both effective and economical [77]. Non-physician health care workers are able, with careful training and supervision, to deliver equal and sometimes better results than doctors; similarly there is now considerable evidence regarding the possibility of shifting tasks from professionals or midlevel workers to lay or community health workers. Perhaps most importantly, task shifting seems to substantially expand access to HIV interventions, even in underserviced areas.

The studies identified in the literature review are marked by substantial heterogeneity [78,79], and highlight several gaps in current research on task shifting. In particular, more research is needed on how the social dynamics in health care teams may be affected by taskshifting policies, as are broader approaches to assessing the outcomes of certain aspects of task shifting, including the management of HAART by cadres lower than nurses. In this regard, while data emerging from randomized controlled trials are important, this approach is unlikely to be the most appropriate, since such complex studies are unlikely to yield data in time to inform such a rapidly changing environment. Nevertheless, our assessment of methodological quality highlights some considerations for improving the design and analysis of future studies. Another important gap relates to the analysis of professional, regulatory and other barriers to policy change in specific contexts.

This review used a comprehensive search strategy that included multiple databases and grey literature sources. 
The fact that over half of the studies that comprised the core of this review are not yet published in peer-reviewed journals is both strength and a limitation of this review. The aim of systematic reviews is to assemble data from both published and unpublished sources to minimize publication bias. However, the inclusion of unpublished studies may lead to the reporting of problematic information that would otherwise be noted during peer reviews.

Policies on task shifting must be considered in context. Firstly, decisions of exactly which type of task shifting (involving doctors, nurses, community health workers, or patients) to implement will also have to be made according to each country context where task shifting will involve a different set of politics, professional and social dynamics, and resource and training needs. This will determine, in line with available evidence, which cadres can reliably perform which tasks, where to set performance thresholds, and how to ensure the best fit with existing roles and scopes of practice. The importance of processes surrounding task shifting are a recurring theme in the literature: appropriate integration into staff structures, adequate pay, and ongoing support and supervision, all require careful attention. More broadly, task shifting has to be engaged within broader health system goals of building access, equity and responsiveness; and where task shifting involves the mobilisation of community health workers, to questions of community participation and accountability [80].

There appears to be consensus that task shifting alone will not solve human resources problems in HIV services, or in health care more generally, in areas with substantial staff shortages and failing health systems. Indeed, health care worker shortages remain a major impediment to the scale-up of antiretroviral therapy in sub-Saharan Africa. Nor should task shifting be considered simply as a means of saving money: while it makes for more efficient uses of clinical resources, in contexts of worker shortages task shifting is primarily a means of extending access to quality care to a greater number of people. Ultimately, task shifting may offer cost-effectiveness rather than cost-savings, and will require strong government leadership to ensure an enabling regulatory framework, and adequate training and financing [80].

In conclusion, our literature review finds that task shifting is a viable and rapid response to sub-Saharan Africa's human resources crisis in HIV care. Carefully focused action is needed at this stage, not to determine whether task shifting is possible or effective, but to define the limits of task shifting and determine where it can have the strongest and most sustainable impact.

\section{Additional material}

Additional file 1 Assessment of methodological quality.
Competing interests

The authors declare that they have no competing interests.

\section{Authors' contributions}

MC conducted the primary literature review and drafted the manuscript. HS conceived of the review, participated in its design, and helped to draft the manuscript. NF undertook supplementary literature reviews and contributed to the writing of the manuscript. All authors have read and approved the final manuscript.

\section{Acknowledgements}

The authors wish to acknowledge the important contribution of Sharonann Lynch to this review in identifying material, and Stephanie Bartlett for a thorough editorial review. $\mathrm{MC}$ received funding to conduct the review from the Association of Universities and Colleges of Canada (AUCC).

\section{Author Details}

'Department of Anthropology, University of Toronto, Canada, ${ }^{2}$ Médecins Sans Frontières, Cape Town, South Africa and ${ }^{3}$ Centre for Infectious Disease Epidemiology and Research, University of Cape Town, South Africa

Received: 5 August 2009 Accepted: 31 March 2010

Published: 31 March 2010

\section{References}

1. WHO/UNAIDS/PEPFAR: Task Shifting: Global Recommendations and Guidelines. Geneva 2008 [http://www.who.int/healthsystems/ task shifting/en/index.html].

2. Heller J: Officiers de Sante: The Second-Class Doctors of NineteenthCentury France. Medical History 1978, 22:1

3. Sidel VW: The Barefoot Doctors of the People's Republic of China. New England Journal of Medicine 1972, 286(24):1292-1300.

4. Mullan F, Frehywot S: Non-physician clinicians in 47 sub-Saharan African countries. Lancet 2007, 370(9605):2158-63.

5. McPake B, Mensah K: Task-Shifting in health care in resource-poor countries. Lancet 2008, 372(9642):870-1.

6. Samb B, Celletti F, Holloway J, Van Damme W, De Cock KM, Dybul M: Rapid Expansion of the Health Workforce in Response to the HIV Epidemic. New England Journal of Medicine 2007, 357(24):2510-14.

7. Laurent M, Reeves D, Hermens R, Braspenning J, Grol R, Sibbald B: Substitution of Doctors by Nurses in Primary Care. Cochrane Database of Systematic Reviews 2005, 1:CD004015.

8. Lehmann U, Sanders D: Community Health Workers: What do we Know About Them? The State of Evidence on Programmes, Activities, Costs and Impact on Health Outcomes of Using Community Health Workers Geneva: World Health Organization: Evidence and Information for Policy; 2007.

9. Lewin SA, Dick J, Pond P, Zwarenstein M, Aja G, van Wyk B, BoschCapblanch X, Patrick M: Lay Health Workers in Primary and Community Health Care. Cochrane Database of Systematic Reviews 2005, 1:CD004015.

10. Laurent M, Reeves D, Hermens R, Braspenning J, Grol R, Sibbald B: Substitution of Doctors by Nurses in Primary Care. Cochrane Database of Systematic Reviews 2004, 4:CD001271.

11. World Health Organization: Integrated Management of Adolescent and Adult Illness. 2004 [http://www.who.int/3by5/publications/documents/ imai/en/. Geneva: WHO

12. World Health Organization: Treat train retain. Task shifting: Global recommendations and guidelines. Geneva 2007 [http://www.who.int/ healthsystems/task shifting/en/.

13. Zelnick J, O'Donnell M: Expansion of the Health Workforce and the HIV Epidemic. New England Journal of Medicine 2008, 358(5):1639-40.

14. Philips M, Lynch S, Massaquoi M, Janssens V, Harries A: Task Shifting for HIV/AIDS: Opportunities, Challenges and Proposed Actions for subSaharan Africa. Transactions of the Royal Society of Tropical Medicine and Hygeine 2009, 103(6):549-58.

15. Gaede B: Rural ARV Provision - Policy Implications for Accelerated ARV Rollout. Southern African Journal of HIV Medicine 2006:23-5.

16. Schneider H, Blaauw D, Gilson L, Chabikuli N, Goudge J: Health Systems and Access to Antiretroviral Drugs for HIV in Southern Africa: Service Delivery and Human Resources Challenges. Reproductive Health Matters 2008, 14(27):12-23. 
17. Philips M, Zachariah R, Venis S: Task Shifting for Antiretroviral Treatment Delivery in sub-Saharan Africa: Not a Panacea. Lancet 2008, 371(9613):682-4

18. Ojikutu B: The Realities of Antiretroviral Rollout: Overcoming Challenges to Successful Programmatic Implementation. Journal of Infectious Disease 2007, 196(Suppl. 3):S445-8.

19. van Rensburg DH, Steyn F, Schneider H, Loffstadt L: Human Resources Development and Antiretroviral Treatment in Free State Province, South Africa. Human Resources for Health 2008, 6:15.

20. Yu D, Souteyrand Y, Banda MA, Kaufman J, Perriëns JH: Investment in HIV/ AIDS Programs: Does it help Strengthen Health Systems in Developing Countries? Global Health 2008, 4:8.

21. Calpin-Davies PJ, Akehurst RL: Doctor-Nurse Substitution: The Workforce Equation. Journal of Nursing Management 1999, 7(2):71-9.

22. Doherty TM, Coetzee M: Community Health Workers and Professional Nurses: Defining the Roles and Understanding the Relationships. Public Health Nursing 2005, 22(4):360-265.

23. Schneider $\mathrm{H}$, Hlophe $H$, van Rensburg D: Community Health Workers and the Response to HIV/AIDS in South Africa: Tensions and Prospects. Health Policy and Planning 2008, 23(3):179-87.

24. Stilwell B, Wilson A, McCaffery J: Non-Physician Clinicians in sub-Saharan African Countries. The Lancet 2008, 371(9624):1578.

25. Chung J, O'Brien M, Price J, Shumbusho F: Quantification of Physiciantime Saved in a Task Shifting Pilot Program in Rwanda. AIDS 2008 - XVII International AIDS Conference. Abstract no. WEAB0205.

26. O'Brien ME, Chung J, Binagwaho A: Nurse delivery of HIV care: Modeling the impact of task-shifting on physician demand. in press. (personal communication).

27. Torpey KE, Kabaso ME, Mutale LN, Kamanga MK, Mwango AJ, Simpungwe J, Suzuki C, Mukadi YD: Adherence Support Workers: A Way to Address Human Resource Constraints in Antiretroviral Treatment Programs in the Public Health Setting in Zambia. PLOS ONE 2008, 3(5):e2204.

28. Udegboka N, Moses John H: Reduction of client waiting time through task shifting in Northern Nigeria. 5th IAS Conference on HIV Pathogenesis, Treatment and Prevention, Cape Town, 2009. Abstract CDD091.

29. McGuire M, Goossens S, Kukasha W, Ahoua L, Le Paih M, Munger A Kabwinja A, Mpunga J, Chazel E, Jeannin A, Szumilin E, Kamoto K, Harries A: Nurses and medical assistants taking charge: task-shifting HIV care and HAART initiation in resource-constrained and rural Malawi. Oral Abstract Session: AIDS 2008 - XVIII International AIDS Conference: Abstract WEPE0106.

30. Kosgei R, Wools-Kaloustian K, Braitstein P, Sidle J, Sang E, Gitau J, Sitienei J, Owino R, Tierney W, Mamlin J, Kimaiyo S, Siika A: Express Care: a cliniciannurse model for the management of high volume HIV clinics in Western Kenya. Oral Abstract Session: AIDS 2008 - XVII International AIDS Conference: Abstract WEAX0102

31. Harling G, Bekker LG, Wood R: Costs of a Dedicated ART Clinic. South African Medical Journal 2007, 97:8.

32. Stearns B, Evans D, Lutung P, Wagner G, Ryan G, Aledort J: Primary estimates of the costs of ART care in South Africa and Uganda. AIDS 2008 - XVIII International AIDS Conference: Abstract MOPEO706

33. Bussmann C, Rotz P, Ndwapi N, Baxter D, Bussmann H, Wester CW, Ncube P, Avalos A, Mine M, Mabe E, Burns P, Cardiello P, Makhema J, Marlink R: Strengthening Healthcare Capacity Through a Responsive, CountrySpecific, Training Standard: The KITSO AIDS Training Program's Support of Botswana's National Antiretroviral Therapy Rollout. Open AIDS Journal 2008 in press.

34. Gimbel S, Durao Mola O, Assan A, Manjate R, Sheer K: Rolling Out ART in Mozambique 2003-2006: Task Shifting and Decentralization. Abstract 90: 2007 HIV/AIDS Implementers'Meeting, Kigali, Rwanda, 16-19 June 2007 [http://www.hivimplementers.net/2007/agenda/Apstracts-AgendaDay2.html].

35. Koenig SP, Leandre F, Farmer P: Scaling up HIV Treatment Programmes in Resource-Limited Settings: The Rural Haiti Experience. AIDS 2004 18(Supplement 3):S21-5.

36. Massaquoi M, Zachariah R, von Pilar U: Task-Shifting in HIV/AIDS Care in a Rural District of Malawi: Some Successes and Lessons Learned from Thyolo. AIDS 2008 - XVIII International AIDS Conference. Abstract WEAB0202.

37. Giorgis B, Bekele R, Tafesse M, Admassu A, Alemu A, Berhanu S, Merdassa G, Tizazu G, Zewde A, Melaku Z: Point of service rapid HIV testing: a key strategy for scaling-up of provider-initiated counseling \& testing. HIV/
AIDS Implementers' Meeting Windhoek, Namibia. June 10-14, 2009. Abstract 700 .

38. Hulela E, Puvimanasinghe J, Ndwapi N, Ali A, Avalos A, Mwala P, Gaolathe $\mathrm{T}$, Seipone $\mathrm{K}$ : Task shifting in Botswana: empowerment of nurses in ART roll-out. AIDS 2008 - XVII International AIDS Conference. Abstract WEPE0108.

39. Morris MB, Chapuli $B, C$ i $B$, et al:: Use of task-shifting to rapidly scale-up HIV treatment services: experiences from Lusaka, Zambia. BMC Health Services Research 2009, 9:5

40. Bedelu M, Ford N, Hilderbrand K, Reuter H: Implementing Antiretroviral Therapy in Rural Communities: the Lusikisiki model of decentralized HIV/AIDS Care. Journal of Infectious Disease 2007, 196(Supplement 3):S464-8.

41. Assan A, Mussa A, Ramirez L, Mckinney M, Nelson L: Task shifting mechanisms for scaling up HIV services in Mozambique. AIDS 2008 XVII International AIDS Conference. Abstract MOPE0798.

42. Chiambe G, Kulzer J, Nyabiage L, Bukuzi E, Penner J, Cohen C: Maximizing human resources by involving lay health workers in HIV service delivery in Kenya. 5th IAS Conference on HIV Pathogenesis, Treatment and Prevention, Cape Town, 2009. Abstract TUPED091.

43. Mareverwa J, Bhembe B, Kamiru H, Shabangu P, Kim J, Mccollum A, Mccollum D, Sibandze M, Mahuma O, Adler M, Amzel A, Pittman R, Henderson F: Impact of task-shifting and joint efforts in the provision of care and antiretroviral treatment to infants and children in a resource constrained setting. AIDS 2008 - XVIII International AIDS Conference: Abstract LBPE1151

44. Jouquet G, Bemelmans M, Massaquoi M, Arnould L, Mwagomba B, Bauernfeind A, Philips M: Cost analysis of an ARV care programme reaching universal access in Thyolo, Malawi. 5th IAS Conference on HIV Pathogenesis, Treatment and Prevention, Cape Town, 2009. Abstract TUAD105

45. Wood R, Fox M, Conradie F, Cornell M, Dehlinger M, Heiberg C, Ingram C, Ive P, Orrell C, Panchia R, Rassool M, Stevens W, Truter H, Horst C van der, Zeinekcer J, Mcintyre J, Sanne I: Nurse Management is not Inferior to Doctor Management of Antiretroviral Naïve HIV Infected Patients. Conference Abstract, 5th IAS Conference on HIV Pathogenesis, Treatment and Prevention, Cape Town, 2009. July 22 2009. Abstract LBPED03

46. Van Rie A, Mbonze N, Tillerson K, Kitenge F, Roger I, Driessche K Vanden, Behets F: A nurse-centered primary health care model for HIV care of patients with active tuberculosis: antiretroviral treatment initiation decision-making. 5th IAS Conference on HIV Pathogenesis, Treatment and Prevention, Cape Town, 2009. Abstract TUPED133

47. Shumbusho F, Turate I, Price J, Lowrance D, Binagwaho A: Task Shifting to Achieve Universal Access to HIV Care: Evaluation of a Pilot Program of Antiretroviral Treatment Service Delivery by Nurses in Rwanda. 2008 HIV/AIDS Implementers meeting, Kampala, Uganda. Abstract 621.

48. Gimbel-Sherr K, Augusto O, Micek M, Gimbel-Sherr S, Tomo M, Pfeiffer J, Gloyd S: Task shifting to mid-level clinical health providers: an evaluation of quality of ART provided by tecnicos de medicina and physicians in Mozambique. AIDS 2008 - XVII International AIDS Conference: Abstract WEAX0105

49. Shulman D, Jobarteh K, Makani E, Mtewa S, Mapwelemwe A, Manjomo A, Crocker J, Joseph K: Task-shifting in the pharmacy: a framework for expanding and strengthening services in rural Malawi. 5th IAS Conference on HIV Pathogenesis, Treatment and Prevention, Cape Town, 2009 Abstract CDD094.

50. Bolton-Moore C, Mubiana-Mbewe M, Cantrell RA, Chintu N, Stringer EM Chi BH, Sinkala M, Kankasa C, Wilson CM, Wilfert CM, Mwango A, Levy J, Abrams EJ, Bulterys M, Stringer JS: Clinical Outcomes and CD4 Cell Response in Children Receiving Antiretroviral Therapy in Primary Health Care Facilities in Zambia. Journal of the American Medical Association 2007, 298(16):1888-99.

51. Chang LW, Alamo S, Guma S, Christopher J, Suntoke T, Omasete R, Montis JP, Quinn TC, Juncker M, Reynolds SJ: Two-Year Virologic Outcomes of an Alternative AIDS Care Model: Evaluation of a Peer Health Worker and Nurse-Staffed Community-Based Program in Uganda. Journal of Acquired Immune Deficiency Syndrome 2009, 50:276-282.

52. Assan A, Mudender F, Brentlinger P, Vallejo J, Bacon O, Martinez P, Ghee A, Branigan E, Smith M: Task-shifting in Mozambique: evaluating antiretroviral therapy as newly implemented by mid-level health professionals. Task-shifting in Mozambique: evaluating antiretroviral therapy as newly implemented by mid-level health professionals. AIDS 2008 - XVII International AIDS Conference. Abstract MOPE0790. 
53. Tootla F, Buhlungu N, Okongo B, Farthing C, Ritchey G, Khanlou H, McKellar M: Successful task shifting at an antiretroviral therapy (ART) clinic in South Africa: a good clinic model for resource-limited settings. 4th IAS Conference on HIV Pathogenesis, Treatment and Prevention, Sydney. Abstract CDB287.

54. Anon: Nurse-driven, community-supported HIV/AIDS treatment at the primary health care level in rural Lesotho. 2009 [http://www.msf.org.za/ Docs/Lesotho/MSF Lesotho Programme Report 2006-2008 .pdf.pdf]. Médecins Sans Frontières, Johannesburg

55. Cohen R, Lynch S, Bygrave H, Eggers E, Vlahakis N, Hilderbrand K, Knight L, Pillay P, Saranchuk P, Goemaere E, Makakole L, Ford N: Antiretroviral treatment outcomes from a nurse-driven, community-supported HIV/ AIDS treatment programme in rural Lesotho: observational cohort assessment at two years. Journal of the International AIDS Society 2009, 12:23.

56. Shumusho F: Task Shifting to Achieve Universal Access to HIV Care and Treatment Services in Rwanda: A Nurse-Centered ART Program at Three Rural Health Centres. Abstract 621: 2008 HIV Implementers'Meeting, Kampala, Uganda, 3-7 June 2008 [http://www.hivimplementers.com/ 2008/default.asp]

57. Van Griensven J, De Naeyer L, Uwera J, Asiimwe A, Gazille C, Reid T: Success With Antiretroviral Treatment for Children in Kigali, Rwanda: Experiences with Health Center/Nurse-Based Care. BMC Paediatrics 2008, 8:39.

58. Shumbusho F, van Griensven J, Lowrance D, Turate I, Weaver MA, Price J, Binagwaho A: Task shifting for scale-up of HIV care: evaluation of nursecentered antiretroviral treatment at rural health centers in Rwanda. PLoSMed 2009, 6(10):

59. Jaffar S, Amuron B, Foster S, Birungi J, Levin J, Namara G, Nabiryo C, Ndembi N, Kyomuhangi R, Opio A, Bunnell R, Tappero JW, Mermin J, Coutinho A, Grosskurth H, Jinja Trial Team: Rates of virological failure in patients treated in a home-based versus a facility-based HIV-care model in Jinja, southeast Uganda: a cluster-randomised equivalence trial. Lancet 2009, 374(9707):2080-9.

60. Mermin J, Were W, Ekwaru JP, Moore D, Downing R, Behumbiize P, Lule JR, Coutinho A, Tappero J, Bunnell R: Mortality in HIV-infected Ugandan adults receiving antiretroviral treatment and survival of their HIVuninfected children: a prospective cohort study. Lancet 2008 371(9614):752-9.

61. Weidle PJ, Wamai N, Solberg P, Liechty C, Sendagala S, Were W, Mermin J, Buchacz K, Behumbiize P, Ransom RL, Bunnell R: Adherence to Antiretroviral Therapy in a home-Based AIDS Care Programme in Rural Uganda. Lancet 2006, 368(9547):1556-7.

62. Alamo-Talisuna S: Task shifting, a strategy to overcome the human resource crisis in HIV/AIDS programs in Uganda. 4th IAS Conference on HIV Pathogenesis, Treatment and Prevention. Abstract CDB281.

63. Zachariah $R$, Teck R, Buhendwa L, Fitzgerald M, Labana S, Chinji C, Humblet $P$, Harries A: Community support is associated with better antiretroviral treatment outcomes in a resource-limited rural district in Malawi. Trans R Soc Trop Med Hyg 2007, 101(1):79-84.

64. Tweya H, Nsona D, Weigel R, Phiri S, Jahn A: Effectiveness of screening for ART eligibility by non-medical HIV testing counsellors. XVII International AIDS Conference, Mexico, 3-8 August, 2008. Abstract WEAB0203.

65. Apondi R, Bunnell R, Awor A, Wamai N, Bikaako-Kajura W, Solberg P, Stall RD, Coutinho A, Mermin J: Home-Based Antiretroviral Care is Associated with Positive Social Outcomes in a Prospective Cohort in Uganda. Journal of Acquired Immune Deficiency Syndrome 2007, 44(1):71-6.

66. Tugume G, Jjuko G, Ssali L: Task shifting - an approach for expanding quality and cost effective community antiretroviral therapy. 5th IAS Conference on HIV Pathogenesis, Treatment and Prevention, Cape Town, 2009 Abstract CDD077.

67. Tantchou Yakam JYC, Gruénais M-E: Involving New Actors to Achieve ART Scaling-Up: Difficulties in an HIV/AIDS Counselling and Testing Center in Cameroon. International Nursing Review 2009, 56:50-7.

68. Tobi P, George G, Schmidt E, Renton A: Antiretroviral Treatment and the Health Workforce in South Africa: How Have ART Workers been Affected by Scaling Up? Tropical Medicine and International Health 2008, 13(12):1452-8.

69. Arem H, Nakyanjo N, Kagaayi J, Mulamba J, Laks R, Nakigozi G, Serwadda D, Quinn T, Gray R, Bollinger R, Reynolds S, Chang L: Peer health workers and AIDS care in Rakai, Uganda: a mixed methods process evaluation of a cluster-randomized trial. 5th IAS Conference on HIV Pathogenesis, Treatment and Prevention, Cape Town, 2009. Abstract CDD100.

70. Sherr K, Manjate R, Gimbel S, Pfeiffer JS, Gloyd S: Policymaker and clinician perspectives towards task shifting for HIV care and treatment in Mozambique: a cross-sectional study. 5th IAS Conference on HIV Pathogenesis, Treatment and Prevention, Cape Town, 2009. TUPED129.

71. Hiner C, Mwale G, Parsons M, Adair M, Reis P, Hughes R: Evaluation of a task-shifting program implemented to increase access to ART in Uganda and Zambia. AIDS 2008 - XVIII International AIDS Conference: Abstract MOPE0097.

72. Suri A, Gan K, Carpenter S: Voices from the Field: Perspectives from Community Health Wokers on Health Care Delivery in KwaZulu-Natal, South Africa. Journal of Infectious Diseases 2007, 196(Supplement 3):S505-11.

73. Sanjana P, Torpey $P$, Schwarzwalder A, Simumba C, Kasonde P, Nyirenda L, Kapanda P, Kakungu-Simpungwe M, Kabaso M, Thompson C: Taskshifting HIV counselling and testing services in Zambia: the role of lay counsellors. Human Resources for Health 2009, 7:44

74. Chang LW, Kagaayi J, Nakigozi G, Packer AH, Serwadda D, Quinn TC, Gray $\mathrm{RH}$, Bollinger RC, Reynolds SJ: Responding to the Human Resource Crisis: Peer Health Workers, Mobile Phones, and HIV Care in Uganda. AIDS Patient Care and STDs 2008, 22(3):173-4.

75. Kober K, Van Damme W: Expert Patients and AIDS Care: A Literature Review on Expert Patient Programmes in High-Income Countries, and an Exploration of their Relevance for HIV-AIDS Care in Low-Income Countries with Severe Human Resource Shortages. 2006 [http:// www.equinetafrica.org/bibl/docs/KOBaids.pdf

76. Labonte R, Torgerson R: Interrogating Globalization, Health and Development: Towards a Comprehensive Framework for Research, Policy and Political Action. Critical Public Health 2005, 15(2):157-79.

77. Dovlo D: Using Mid-Level Cadres as Substitutes for Internationally Mobile Health Professionals in Africa: a Desk Review. Human Resources for Health 2004, 2(1):7.

78. Scott A, Vale L: Increased General Practice Workload due to a Primary Care led National Health Service: the need for Increased Evidence to Support Rhetoric. British Journal of General Practice 1998, 48(428):1085-8.

79. Swider SM: Outcome Effectiveness of Community Health Workers: An Integrative Literature Review. Public Health Nursing 2002, 19(1):11-20.

80. Lehmann U, Van Damme W, Barten F, Sanders D: Task shifting: the answer to the human resource crisis in Africa? Human Resources for Health 2009, 7:49.

\section{doi: $10.1186 / 1478-4491-8-8$}

Cite this article as: Callaghan et al., A systematic review of task- shifting for HIV treatment and care in Africa Human Resources for Health 2010, 8:8

\section{Submit your next manuscript to BioMed Central and take full advantage of:}

- Convenient online submission

- Thorough peer review

- No space constraints or color figure charges

- Immediate publication on acceptance

- Inclusion in PubMed, CAS, Scopus and Google Scholar

- Research which is freely available for redistribution 